\title{
“Tantas, sou só uma e sou tantas"1
}

"Soy solo una y soy tantas"

"So many... I'm only one, yet I'm so many"

\section{Patrícia Abel Balestrin}

UNILASALLE, Canoas, RS, Brasil.

\section{Resumo}

O presente artigo toma como ponto de partida o longa-metragem "O Céu de Suely", dirigido por Karim Aïnouz (2006), e lança um olhar possível sobre alguns itinerários de gênero e de sexualidade experimentados pela protagonista do filme. O mergulho nesse filme específico é regido tanto pelo aporte teórico que sustenta esse trabalho, especialmente a teorização desenvolvida por Judith Butler em composição com os estudos foucaultianos em torno da sexualidade e do poder, como pelo recurso metodológico escolhido - "etnografia de tela". Alguns pontos de análise são enfatizados neste trabalho: a minha implicação no ato de ver esse filme e de trabalhar com essa temática; o dispositivo da sexualidade na vida das mulheres; fragmentos fílmicos para pensar o conceito de performatividade de gênero em cena-ação. Diria que o filme em análise aponta para possibilidades de resistência e subversão e, no mesmo instante, aciona performativos de gênero e de sexualidade.

Palavras-chave: Gênero, Sexualidade, Performatividade, Mulheres.

\section{Resumen}

El presente artículo toma como punto de partida la película "El Cielo de Suely", dirigido por Karim Aïnouz (2006), y lanza un mirar posible sobre algunos itinerarios de género y sexualidad vividos por la protagonista del filme. El sumergirse en ese filme específico es regido tanto por el aporte teórico que sustenta ese trabajo, especialmente la teorización desarrollada por Judith Butler en composición con los estudios foucaultianos en torno de la sexualidad y del poder, como por el recurso metodológico elegido denominado etnografía de tela. Algunos puntos de análisis son enfatizados en este trabajo: mi implicación en el acto de ver esa película y de trabajar con esa temática; el dispositivo de la sexualidad en la vida de las mujeres; fragmentos fílmicos para pensar el concepto de performatividad de género en escena-acción. Finalmente, afirmo 
que el filme en análisis apunta para posibilidades de resistencia y subversión al mismo tiempo en que reitera performativos de género y sexualidad.

Palabras-claves: Género, Sexualidad, Performatividad, Mujeres.

\begin{abstract}
This paper analyses the film "O Céu de Suely" (Love for sale: Suely in the sky, 2006), directed by Karim Aïnouz, trying to follow the trajectory of the protagonist (Hermila) and her gender and sexuality performances. The study of this particular film was based upon gender and queer studies, especially on the approach developed by Judith Butler, in composition with the Foucauldian studies on sexuality and power relations. The methodology chosen was the "ethnography of the screen". Some points of the analysis are emphasized in the present paper: my implication in the act of watching this film and with the topics related to gender and sexuality; the effects of the apparatus of sexuality in the lives of women; some fragments of the film that helped me think the concept of gender performativity in the scenes. Finally, I point to the possibilities of resistance and subversion, as well as reiteration, of gender and sexuality norms.
\end{abstract}

Keywords: Gender, Sexuality, Performativity, Women.

O presente trabalho é um recorte de minha pesquisa ${ }^{2}$ intitulada $O$ Corpo Rifado na qual analisei enunciados performativos que se articulam em torno do gênero, da sexualidade e da brasilidade. A pesquisa tomou como ponto de partida o longametragem dirigido por Karim Aïnouz (2006), O Céu de Suely, que narra a história de Hermila, uma jovem que volta de São Paulo para sua cidade natal, no interior do Ceará, com seu filho pequeno. Ela aguarda a chegada de seu amor, Mateus. Logo ela se dá conta de que ele não cumprirá com a promessa de encontrála.

Diante disso, Hermila cria estratégias de sobrevivência enquanto sonha em sair daquele lugar, custe o que custar.

O mergulho nesse filme específico foi regido tanto pelo aporte teórico que sustentou a pesquisa, especialmente a teorização desenvolvida por Judith Butler em composição com os estudos foucaultianos em torno da sexualidade e do poder, como pelo recurso metodológico escolhido - "etnografia de tela". 
A partir do (e com o) filme, questiono: Que enunciados performativos são reiterados para a constituição de uma suposta identidade feminina? Que enunciados indicam possibilidades de resistência, subversão e ressignificação? Que outros enunciados parecem manter normas regulatórias do gênero e da sexualidade? Como a linguagem cinematográfica empregada neste filme produz sentidos, provoca deslocamentos, desestabiliza, mantém, visibiliza e invisibiliza determinados modos de ser mulher? Ainda que essas questões não sejam assertivamente respondidas neste trabalho, elas indicam um percurso. No recorte de pesquisa que apresento aqui enfatizo alguns pontos de análise, tais como: a minha implicação no ato de ver esse filme e de trabalhar com essa temática; o dispositivo da sexualidade na vida das mulheres; fragmentos fílmicos para pensar o conceito de performatividade de gênero em cena-ação.

A análise de um filme opera um duplo trabalho: a análise trabalha o filme e trabalha também o/a analista, segundo Vanoye \& Goliot-Lété (2006, p. 12-13). Diria que qualquer tipo de análise pode operar esse duplo trabalho. No decorrer da pesquisa, o sujeito pesquisador é também trabalhado, na medida em que é interpelado, transformado, desfeito, reconfigurado. Trata-se de um caminho analítico no qual o próprio ato de olhar transforma quem vê e o que vê.

Nesse sentido é preciso reconhecer de que lugar assisto ao filme, o que e como ele me provoca/convoca. Os processos desencadeados no ato de ver um filme também fazem parte dos elementos que considero na análise, ou seja, a minha experiência com o filme merecerá uma espécie de "análise de implicação": "Estar implicado (realizar ou aceitar a análise de minhas próprias implicações) é, ao fim de tudo, admitir que eu sou objetivado por aquilo que pretendo objetivar." (Lourau citado por Paulon, 2005, p.23) Embora essa metodologia de pesquisa seja mais difundida no campo da análise institucional e de pesquisas-intervenção, acredito que pude me inspirar nessa abordagem, na medida em que a relação que estabeleci com o filme mereceu uma análise de como estive (e estou) implicada neste ato de ver a tela e de me ver na tela também. Foi possivelmente a partir dessa análise de implicação que pude 'avançar' a própria análise fílmica, no sentido de ampliar sentidos, desconstruir saberes e práticas às quais eu pudesse estar me 'prendendo' no terreno teórico-metodológico que vinha construindo. Acredito que a análise de implicação fez diferença no contexto dessa pesquisa.

Diria que o tema desse estudo é, de certa forma, um tema central em minha 
vida e me remete a situações vividas em outros tempos. Cito como exemplo o hábito que eu tinha na 'adolescência'3 $\mathrm{de}$ 'passar os olhos' nas revistas femininas que minha mãe lia na época (final dos anos 1980). Lembro-me de uma vez ter lido numa das tantas reportagens sobre sexo que constantemente interpelavam (e interpelam) mulheres no exercício de uma determinada sexualidade - uma frase que não esqueci: "quem transa tem um brilho no olhar". Certamente busquei esse brilho no espelho algumas vezes. E não o busco mais? Essa situação não apenas sinaliza meu antigo interesse pelas questões do feminino e da sexualidade, como corrobora a força das pedagogias culturais numa vida.

Em algum momento, durante a pesquisa empreendida no curso de Doutorado, pude reconhecer que estava, de algum modo, falando de uma questão que me ocupa já há algum tempo, uma questão que me instiga, que me fascina, que me alimenta e, ao mesmo tempo, por vezes, me derruba, me tira o chão e abala qualquer certeza na qual pudesse ter me agarrado por algum ou por muito tempo. Refiro-me à relação da mulher com seu corpo e com o prazer, à construção desse corpo feminino e à produção dessa 'feminilidade' em meio a Eros, paixão, desejo, entrega, frustração, raiva, liberdade, prazer, amor, dança, amizade, sedução, sexualidade, cuidado, cumplicidade, violência, conflito, diferença, superação, força, sonho, luta, juventude. Se antes esses temas habitavam um universo considerado mais íntimo e silencioso, ao me aproximar dos estudos de gênero essas temáticas passaram a acionar um posicionamento teórico e político. E nada mais seria como antes...

Enquanto olho para a tela, a tela me olha e me indaga: que mulher é esta que agora escreve? A tela dessa pesquisa perturba alguns modos com os quais já estive (e ainda estaria?) 'identificada' - de repente, já não me encontro na mulher que um dia fui, nem na mulher que hoje estou sendo. Insisto num ponto de resistência que me impeça de me identificar demasiadamente com qualquer uma das identidades já construídas até aqui. Sou isso $e$ aquilo, sou mais $e$ sou menos, sou $e$ não sou a mulher que vejo na tela agora escrita: da vida. E arrisco dizer: ainda bem que aquelas que fui não sobreviveram em mim.

\section{Mulheres e o dispositivo da sexualidade}

Foucault (1989, 2005a), em diversos estudos, buscou analisar os processos envolvidos na produção de 'verdades': como 'uma verdade' torna-se 'a verdade'? No que se refere à sexualidade, em entrevista com Bernard 
Henri-Lévy, o autor questionou: "Como é possível que ela tenha sido considerada como o lugar privilegiado em que nossa 'verdade' profunda é lida, é dita?" (Foucault, 1989, p. 229).

Nessa mesma entrevista intitulada “Não ao Sexo Rei”, Foucault (1989) chega a mencionar que tentaria mais tarde fazer um estudo do processo de patologização da mulher - o que infelizmente não se concretiza $^{4}$. $\mathrm{O}$ autor afirma que:

Durante muito tempo se tentou fixar as mulheres à sua sexualidade. "Vocês são apenas o seu sexo", dizia-se a elas há séculos. E este sexo, acrescentaram os médicos, é frágil, quase sempre doente e sempre indutor de doença. "Vocês são a doença do homem". (...) o corpo da mulher torna-se objeto médico por excelência. (Foucault, 1989, p. 234).

$\mathrm{O}$ autor menciona o desafio aceito pelo movimento feminista que - mesmo partindo do dispositivo da sexualidade buscava naquele momento outras afirmações relativas ao corpo e ao prazer das mulheres. Foucault (2005a), como sabemos, desconstrói a hipótese de ter sido o sexo reprimido a partir do século XVIII, e afirma: "Não digo que a interdição do sexo é uma ilusão; e sim que a ilusão está em fazer dessa interdição do sexo o elemento fundamental e constituinte a partir do qual se poderia escrever a história do que foi dito do sexo a partir da Idade Moderna.” (p.17) O autor sintetiza: “Em suma, trata-se de determinar, em seu funcionamento e em suas razões de ser, o regime de poder-saber-prazer que sustenta, entre nós, o discurso sobre a sexualidade humana." O ponto essencial seria:

levar em consideração o fato de se falar de
sexo, quem fala, os lugares e os pontos de
vista de que se fala, as instituições que
incitam a fazê-lo, que armazenam e
difundem o que dele se diz, em suma, o
"fato discursivo" global, a "colocação do
sexo em discurso". (Foucault, 2005a, p.
16)

Numa direção semelhante, Swain (2006) instiga-nos a pensar nessa proliferação do "sexo em discurso". A autora inicia o texto "Entre a vida e a morte, o sexo" de forma provocativa:

\footnotetext{
"Sexo é vida" repete incansavelmente uma propaganda na TV. Ejaculação precoce? Falta de desejo? Pela internet recebo dezenas de mensagens: ative seu apetite sexual! frigidez? tome viagra, melhore seu desempenho! aumente seu pênis! mas eu não tenho pênis, quem sou eu? Libere seus feromônios, não sabe que o cheiro é sedução? Dança do ventre, pompoarismo, preciso me atualizar, perder esta barriga, levantar os seios, aumentar a bunda, ai esta celulite, e o dinheiro para a plástica?

Onde está meu perfume, meu xampu, meus cremes para tudo, preciso depilar a virilha, que cabelo mais crespo, ninguém assobia
} 
para mim, ninguém me olha, quem sou eu? meu desodorante venceu, estou suando, que roupa antiga, não transei esta semana, não tive nenhuma paquera, ninguém me disse que eu estava sexy, o que é ser sexy afinal? quem sou eu, não consigo seduzir, estou só, só, não sinto desejo, preciso me tratar, será que morri? quem sou eu? não casei, não tenho filhos, não sou mulher? não tenho pênis, não sou homem, quem sou eu?

A autora problematiza os tantos imperativos que governam nossas vidas e o quanto o "dispositivo da sexualidade" está em ação e precisa ser constantemente 'renovado' com tecnologias e estratégias diversas. "O dispositivo, portanto, inventa os corpos e os possui, cria-os ao defini-los e moldá-los enfatizando o prazer, sem defini-lo nem questioná-lo, para melhor apagar os traços de sua construção e domesticação.” (Swain, 2006)

A forma como entendo o conceito de sexualidade neste ensaio é, pois, como Foucault (2005a) a define: um dispositivo histórico e contingente que reúne práticas sociais em torno do corpo, seus usos e prazeres. Vale lembrar que ele entende dispositivo como um conjunto de estratégias de poder e saber que se ligam a determinados discursos para que exerçam efeitos de verdade. Sobre o dispositivo de sexualidade, podemos pensar que foi preciso que 'a verdade' sobre o sexo fosse dita e disseminada para que pudesse reger os comportamentos e desejos dos sujeitos de uma cultura. Ainda hoje, vemos essa "vontade de saber" muito associada ao sexo e à sexualidade.

Acredito que essa vontade de saber associada à sexualidade produz pedagogias que atualizam ou integram o dispositivo, produzindo não apenas saberes e práticas em torno do corpo e seus prazeres - elas produzem também sujeitos detentores de um sexo, de um gênero e de uma sexualidade. Essas pedagogias - tão presentes na mídia de um modo geral e no cinema de modo especial - têm promovido verdades sobre esses sujeitos; revigorado normas e as transformado; produzido modos aceitáveis e inaceitáveis de viver. Elas funcionam como performativos que interpelam e induzem os sujeitos a viver a sexualidade de determinadas formas. Certamente eles também estão em funcionamento no filme alvo desta "etnografia de tela".

\section{Etnografar alguns itinerários de gênero e de sexualidade na tela}

A jornalista e antropóloga Rial (2005) adota o termo "etnografia de tela" para referir-se, especificamente, a estudos de textos da mídia em que emprega procedimentos próprios da pesquisa etnográfica, aliados a ferramentas próprias 
da crítica cinematográfica. O termo teria surgido dos "estudos de tela" que desde os anos 1980 já se referiam ao estudo etnográfico dos artefatos da mídia.

Para a realização desse tipo específico de etnografia ${ }^{5}$, destaco os seguintes procedimentos adotados: longo período de contato com o campo (neste caso, com o filme); observação sistemática e variada (assistir ao filme de diferentes modos - sem interrupção, com pausas para registro, assistindo aos extras); registro em caderno de campo (tanto da descrição das cenas fílmicas, como de questões e pontos que pareciam potencialmente interessantes para análise); escolha de cenas para análise mais aprofundada. Assim, em relação às ferramentas próprias da linguagem cinematográfica, procurei observar os movimentos da câmera, a iluminação, os componentes dos planos, a trilha sonora, os modos de apresentar as personagens e seus movimentos dentro do filme, as escolhas relativas à montagem e ao modo de narrar a história.

As personagens do filme, embora não interajam comigo, ganham força suficiente para que seus olhares, gestos e atitudes penetrem a minha própria vida, operando não apenas o pensar, o refletir e o analisar sobre os enunciados que estão em jogo - elas me olham tanto quanto eu as olho. ${ }^{6}$ Sou capaz de me identificar com elas não apenas durante as observações e registros no caderno de campo. Elas saem da tela e passam a ocupar outros espaços para além da posição de pesquisadora. A memória que tenho delas pode insurgir a qualquer momento e me fazer ser um pouco outra, ou quem sabe, um pouco menos ou um pouco mais daquilo que sou ou daquilo que fui.

"Me vejo no que vejo
Como entrar por meus olhos
Em um olho mais límpido
Me olha o que eu olho
É minha criação
Isto que vejo
Perceber é conceber
Águas de pensamentos
Sou a criatura
Do que vejo"?

Quando afirmo que meu interesse é perseguir onde, quando, como mulheres conseguem resistir e subverter as normas regulatórias do gênero, num processo de agenciamento, talvez seja preciso antes reconhecer a que normas estou me referindo. Que normas têm interpelado as mulheres na formação de uma suposta ‘identidade feminina'? Que normas têm sido repetidamente citadas na exibição de corpos femininos? Se antes, numa leitura bastante difundida pelas teóricas fílmicas feministas ${ }^{8}$, dizia-se que a mulher aparecia (quase) sempre como objeto de desejo do 
outro (masculino), hoje talvez possamos dizer que, em muitos filmes, ela(s) tornouse (tornaram-se) sujeito(s) desejante(s). Isso não significa que imagens de extrema violência contra - e submissão de mulheres não persistam nas diferentes produções cinematográficas assim como em outros artefatos culturais.

Considerando que a linguagem é performativa - constitui aquilo de que fala, faz as coisas existirem - enquanto escrevo, faço-me (outra) também. Como argumenta Foucault (2001) em seu texto "O que é um autor?": "Na escrita, não se trata da manifestação ou da exaltação do gesto de escrever; não se trata da amarração de um sujeito em uma linguagem: trata-se da abertura de um espaço onde o sujeito que escreve não para de desaparecer.” (p. 268) Se o sujeito é uma ficção necessária, como sugere Butler (1999), aquilo que escreve não seria igualmente uma ficção necessária?

A partir desses questionamentos é que me proponho a etnografar os itinerários de gênero e de sexualidade empreendidos pelas mulheres de um filme. Seguir seus passos. Olhar para onde olham. Ver seus corpos. Caminhar. Pegar a estrada. Apostar.

A 'estrada do gênero' para as mulheres têm apontado, historicamente, um caminho como sendo $o$ ideal, $o$ mais completo, $o$ de uma realização plena, que incluiria: o casamento heterossexual (ainda pautado em princípios do "amor romântico"?), a maternidade, a beleza e a (eterna) juventude. Certamente os movimentos e teorizações feministas já reconheceram alguns equívocos e outras estratégias têm sido movimentadas para repensar caminhos tanto na esfera pública, como na esfera privada. No lugar de superação ou evolução vemos um jogo de forças no qual coexistem velhos $e$ novos ideais associados ao feminino. $\mathrm{E}$ 'os novos' deveriam desmanchar 'o velho'? Por vezes, a tendência é olhar para os avanços e retrocessos como movimentos separados e autônomos. Os termos binários novos e velhos, avanços e retrocessos já carregam em si uma histórica dicotomia/hierarquia. $\mathrm{O}$ próprio olhar estaria encharcado da noção de progresso, evolução, aperfeiçoamento, melhorias no 'setor' do gênero. A conjunção " $e$ " mostrase potente nessa perspectiva teórica que enfatiza a convivência de diferentes possibilidades e significados.

Como se sabe, o modelo dos dois sexos, por exemplo, não desmanchou o antigo modelo de um sexo único (Laqueur, 2011). Diria que o (nem tão) novo modelo carrega até hoje marcas do antigo. No lugar de uma concepção de sexo derrubar a outra, vemos modelos divergentes convivendo e disputando um lugar de 
legitimidade nos discursos da ciência, da biologia, da psicologia e assim por diante.

Movimentos que permitem uma expansão na vida das mulheres convivem com velhas crenças e expectativas que tendem a limitar e paralisar esses movimentos. Não se pode deixar de mencionar os efeitos instigantes que os movimentos feministas e LGBTT (Lésbicas, Gays, Bissexuais, Travestis e Transexuais) possibilitaram para mulheres e homens na contemporaneidade. No entanto, é preciso reconhecer que há uma espécie de 'paraefeitos dos efeitos' - com isso, quero afirmar que não há garantias e soluções instantâneas para os conflitos, dilemas e descasos sofridos em torno das desigualdades de gênero e de sexualidade. Por vezes, numa leitura superficial, colocam-se as relações de poder como não problemáticas: como se isso já estivesse solucionado, como se essa questão já tivesse sido superada, resolvida ou amenizada. Como sacudir com expectativas que teimam, ainda hoje, em cercear as vidas de mulheres e suas escolhas e, de um modo particular, as vidas de mulheres-mães?

Ser esposa, mãe, bela, jovem e sensual parece que continua sendo um imperativo para a maioria das mulheres que, além disso, ainda são interpeladas a obterem realização profissional e sexual. Rosângela Soares (2010, p. 3), ao analisar a força do amor e da paixão na trajetória da protagonista de "O Céu de Suely", problematiza:

\begin{abstract}
É inegável que as mulheres, por meio de lutas sociais, têm modificado as relações de gênero no mundo do trabalho, na vida doméstica, nas relações sexuais e em outros espaços sociais. Com todas essas mudanças, no entanto, parece que ainda persiste a divisão clássica de gênero quando o assunto é assentado nas relações de amor. Serão estas um reduto clássico de distinções de gênero, apesar de todas as mudanças?
\end{abstract}

O desejo de amor parece imperativo na vida de muitas mulheres. Nesse movimento de ideais, há que se reconhecer que, mesmo rompendo com algumas normas da ordem sexo-gênero-sexualidade, mantém-se com bastante força o desejo de ser mãe e a realização através da maternidade. Butler (2003), em estudo intitulado "O parentesco é sempre tido como heterossexual?", problematiza essa produção de desejo que vem atrelada aos moldes do casamento heterossexual e, por conseguinte, ao controle e tutela do Estado. Como aponta a antropóloga brasileira Grossi (2003, p. 267), referindo-se às mobilizações de jovens militantes lésbicas no Brasil, "a temática da parceria civil emergiu como prioridade do movimento lésbico e nela a possibilidade de 
reconhecimento do desejo de maternidade parece ser um forte componente das atuais mobilizações." Nessa luta pelo reconhecimento de um lugar, de uma possibilidade de existência, de uma identidade tida como desviante, há que se perguntar: que instituições parecem ganhar ainda mais força nesse embate?

A questão do casamento e da família parece ocupar, ainda hoje, o centro de muitas vidas. Embora a expectativa quanto à idade de se casar tenha mudado ao longo da história, diria que permanece uma incitação ao casamento heterossexual - enquanto instituição que legitima o lugar da mulher e do homem e, mais do que isso, reafirma um 'valor fundamental': a família. Enquanto alguns autores (Bauman, 2005; Costa, 1999) problematizam instituições que estariam perdendo a força na contemporaneidade (como a família, por exemplo), vemos, por outro lado, uma reafirmação de valores acoplados a essas instituições.

\section{"Ele disse que queria casar comigo ou então morrer afogado".}

Alusões ao casamento aparecem pelo menos em dois fragmentos de "O Céu de Suely": nessa narração que abre o texto fílmico e mais adiante no primeiro diálogo entre Hermila e João (possivelmente seu ex-namorado que ficara em Iguatu), quando esse lhe pergunta: "Cadê teu macho?" ao que ela responde: "Meu marido ta chegando daqui um mês." (grifo meu).

É para a casa de sua família que Hermila retorna com seu bebê; após viver algum tempo em São Paulo com seu marido. Sua família, que permanece em Iguatu, é composta por mulheres: avó e tia. Destaco um diálogo entre Hermila e sua avó que traz à tona um elemento bastante valorizado na constituição das mulheresmães. A avó segura o bebê no colo, após lhe dar banho com entusiasmo. Percebe-se que há uma centralidade da figura do menino nesses primeiros diálogos. Há duas cenas de banho do menino: "O banho da criança no início e no fim do filme marca momentos que dão a dimensão da importância do menino no contexto familiar" (Soares, 2010, p. 4). O banho aqui parece evocar um afeto particular tanto na acolhida como na despedida. Essa 'maternagem' que geralmente é exercida por mulheres sugere fragilidade, carência e incapacidade de um bebê ser/sobreviver sozinho no mundo, além de indicar certa intimidade com aquele corpo infantil. $\mathrm{Na}$ acolhida é a avó Zezita quem acolhe, através do banho, a criança que a família está conhecendo. Antes de partir, é Hermila quem banha o menino, como um gesto íntimo de uma despedida particular. 
De certa forma, ainda que não me pareça o centro da trama, é de se notar que questões que circundam a maternidade são postas em jogo aqui. Hermila e tia Maria estão sentadas à mesa. Zezita parece contente com a presença do bisneto, ela se aproxima de Hermila com o bebê no colo e comenta "Mamamama... ele o tempo todo... Agora, minha filha, eu acho que ele tá com fome.". Hermila diz “É, tá com fome. A senhora faz a mamadeira?". A avó questiona com certo ar de espanto e repreensão: "Você não tá dando de mamá pra ele não minha filha?". A jovem diz que não e a avó comenta: "Tão gordinho, achei que ele tivesse mamando." Hermila justifica: "Não, meu leite secou." [Choro do bebê]

Se folhearmos jornais e revistas da atualidade não será difícil encontrarmos discursos em torno da maternidade. Cuidar, dedicar-se inteiramente a esse cuidado, amar de forma incondicional são algumas das características veiculadas na mídia e nos programas de saúde que posicionam o ser mulher e o ser mãe, muitas vezes, como praticamente sinônimos. Vale ressaltar que teorizações e práticas $p s i^{9}$ contribuíram de forma contundente na produção e reprodução da chamada 'função materna' e seus efeitos no desenvolvimento dos bebês.

Em pesquisa realizada com travestis e transexuais (de homem para mulher), em Curitiba, Adelman e Ruggi (2007, p. 53-54) afirmam que "despontou uma representação bastante convencional do feminino, claramente retomada das definições hegemônicas binárias." Para quase todas as entrevistadas, o feminino está associado a questões relativas ao corpo, à beleza, à vaidade, ao serviço doméstico e, como não poderia faltar, ao chamado "instinto maternal". Nesse contexto, “o 'querer ser mulher' se dá em função do gosto de cuidar dos outros, curtir 'atividades femininas' como cozinha e os cuidados corporais-estéticos ou, ainda, o cuidar de si para poder agradar e ser desejada pelo "sexo oposto"'.

Meyer (2002) faz uma análise cultural em que procura "relacionar as condições de emergência de políticas que definiam a maternidade em articulação com o aleitamento materno nas sociedades ocidentais com a configuração atual dessa política no Brasil" (p.379). ${ }^{10} \mathrm{~A}$ autora nos leva a problematizar discursos que têm se produzido em torno da maternidade e da amamentação desde o século XVIII, mostrando-nos que nem sempre esses discursos convergem e convivem de forma harmônica, pelo contrário, produzem múltiplas e conflitantes representações: "todas as representações de mulher, maternidade ou amamentação produzem sentidos que funcionam competindo entre si, deslocando, acentuando ou suprimindo 
convergências, conflitos e divergências entre diferentes discursos e identidades" e acrescenta: "mas são algumas delas que, dentro de determinadas configurações de poder, acabam se revestindo de autoridade científica e/ou se transformando em senso comum" (p.385). Nesse jogo de verdades, haverá a produção de uma maternidade considerada mais legítima e verdadeira a partir da qual as outras maternidades serão des-qualificadas. Evidentemente é de se perguntar: se algo que é tido como tão natural e instintivo precisaria sofrer tantos processos de pedagogização e disciplinamento.

Numa das cenas iniciais do filme, Hermila está deitada no chão da calçada, fumando um cigarro, em frente à casa de sua avó. Ouve-se o choro de Mateus que está fora de campo e os passos da tia Maria que se aproxima de Hermila. Tia Maria senta-se ao lado de Hermila e pergunta: "Toda noite ele chora desse jeito até dormir, é?" Ao que Hermila responde sorrindo: “É. $A i$, às vezes dá vontade de deixar ele no mato e sair correndo".

$\mathrm{Na}$ mesma cena, vemos Hermila agora sentada na calçada ao lado de tia Maria que indaga: "e tua vida em São Paulo, como era?" - "Era boa”, responde Hermila, "mas lá é tudo caro. Não dava pra ficar mais lá não. Aí a gente decidiu voltar".
Tia Maria passa a mão no cabelo de Hermila que sorri e também passa a mão no próprio cabelo, colocando a cabeça para trás. "E esse cabelinho, é moda lá, é?" Pergunta com curiosidade à Hermila que responde sorrindo - “É a franja.". Tia Maria estranha o fato de Hermila ter pintado apenas a franja do cabelo: "Só pinta a frente?" [close-up de Hermila e de Maria; em meio ao diálogo ouvimos ruídos do ambiente e sons de pássaros] Do rosto que sorri, Hermila passa a uma atmosfera de seriedade e preocupação comentando: "Acho que vó ta cansada... Acho que ela não gostou de me ver aqui não..." Tia Maria discorda: “Oxe, menina, que história é essa? Nunca mais ela tinha feito comida boa assim. Agora ela ta lá olhando tuas fotos pra ver se Mateus se parece com tu”. Hermila sorri e Maria continua: "O que ela não gostou foi do jeito que tu saiu daqui... Fugida, parecendo uma doida. Nem pra mim você deu tchau." De um plano fechado a imagem passa para um plano aberto, as duas se deitam no chão e sorriem. Enquanto Hermila se deita no chão da calçada, diz: "Paixão, tia. A maior paixão do mundo." E tia Maria brinca: “Paixão, foi? Sua descarada!”.

Nesse encontro entre Hermila e sua tia, há muitos elementos instigantes para pensar nas construções de gênero. Esses elementos retornarão nas cenas seguintes do filme; eles disparam as análises 
apresentadas neste texto específico. Escolho enfatizar agora um desses pontos: a maternidade.

Vozes como de Hermila no filme e de estudiosas como Soares (2010) em sua análise do filme parecem romper com uma espécie de pacto de silenciamento sobre 'o outro lado da maternidade': “A possibilidade de movimentar-se só se dá por haver alguém que assume o cuidado do filho. Os filhos são um dos motivos que dificultam as mudanças e os movimentos das mulheres no mundo." (Soares, 2010, p. 5)

Estaria em curso aqui uma desconstrução/ressignificação da maternidade? Em outra cena, Hermila pede a uma amiga balconista para 'guardar' seu filho enquanto vende umas rifas pelo centro da cidade. Não se glorifica, nem se demoniza a maternidade aqui. Não estariam em jogo outros significados possíveis para o ser mãe, para o ser mulher e para o amor?

O psicanalista Birman (2001, p. 6364) argumenta que: "o erotismo tornou-se um pólo contraditório no ser da mulher, que poderia perturbar a vocação reprodutiva do seu corpo. (...) entre o desejo sensual e a maternidade, o corpo feminino seria polarizado." E dessa forma, “(...) $\mathrm{O}$ erotismo feminino era concebido como essencialmente perigoso, pela ameaça de desordem que representava”.
O autor recorda que essa oposição entre maternidade e desejo sensual teria sido formulada no século XIX com o empenho da tradição cristã que “desarticulou os registros do prazer e da reprodução, considerando o primeiro como da ordem do pecado. Constituiu-se, assim, a diabolização do desejo feminino, que poderia desviar as mulheres da existência casta e do caminho virtuoso da maternidade." Havia uma preocupação em silenciar "qualquer dimensão de gozo no corpo feminino". Essa concepção parece ir de encontro à construção das diferenças de gênero que insiste em proclamar que a sexualidade masculina é que seria incontrolável e desenfreada. Às mulheres é possível controlar os desejos e fantasias mais ardentes, aos homens, impossível!

Segundo Birman (2001), a "mulher desejante" passou a se constituir como "mulher perigosa" que deveria ser corrigida em nome da ordem e higiene social. Se, por um lado, o erotismo feminino devia ser silenciado, por outro, o erotismo masculino não se opunha à tarefa reprodutiva, porém, nem tudo o que dele se quisesse poderia ser vivido no seio da família. Conforme aponta Birman (2001, p. 72), “a grande expansão da prática da prostituição, que ocorreu ao longo do século XIX, seria a contrapartida social para que se pudesse definir um lócus 
preciso e bem circunscrito para o exercício do erotismo masculino."

As mulheres que não correspondessem aos desígnios sagrados da maternidade eram, de algum modo, culpabilizadas e consideradas desviantes. Conforme Birman (2001), o discurso médico do século XIX tratou de classificar as práticas desviantes da feminilidade em quatro modalidades: a prostituição, o infanticídio, a ninfomania e a histeria. Essas figurações do feminino consideradas anômalas encontram na recusa da maternidade seu ponto em comum, com exceção da histérica. ${ }^{11}$ No lugar da maternidade, essas mulheres assumiriam o erotismo como uma "dimensão efetiva da existência feminina" (p. 77). Erotismo e maternidade mostram-se, nessa produção de saberes, como "formas inconciliáveis de ser da feminilidade". (p. 79)

Já é sabido que os movimentos e teorizações feministas problematizaram essas construções em torno do corpo feminino e da maternidade na tentativa de ampliar as possibilidades de feminilidades e, em seguimento, de masculinidades. Embora a referência de um dos primeiros textos feministas que li tenha se perdido na memória, recordo-me que ele trazia como ponto de partida o dilema enfrentado por muitas mulheres entre terem ou não terem filhos/as. $\mathrm{O}$ que antes parecia ser inevitável, agora tornava-se uma 'questão de escolha' com o advento de métodos contraceptivos que revolucionaram a vida sexual a partir da década de 1970 . O texto expunha a troca de cartas realizada entre duas mulheres que se questionavam sobre os caminhos que haviam escolhido: uma abdicara de sua vida profissional para viver a maternidade e o casamento de um modo quase exclusivo, enquanto a outra teria abdicado desse destino antes 'natural' para dedicar-se integralmente à realização profissional. Ambas falavam de um vazio, de algo que ficou para trás, de algo que não fora vivido: ressentimento. Ainda que estejamos vivendo um tempo de ressignificações em torno da maternidade e de novas possibilidades para contracepção e concepção, acredito que ainda hoje esse dilema habita a vida de muitas mulheres. Não raramente, ele acompanha outros dilemas comuns relativos ao que, afinal, se esperava e se espera de uma mulher.

Em sua pesquisa sobre imagens de mulher na Revista Educação Physica, periódico publicado entre 1932 e 1945 , Goellner (2003) analisou como essas imagens estavam impregnadas de, pelo menos, três impositivos às mulheres: "seja bela", "seja mãe" e "seja feminina". É, no mínimo, curioso acompanhar os 'resultados' de sua pesquisa e traçar uma breve comparação ao que encontro hoje, nas imagens de mulheres que analiso em um filme. Se os padrões de beleza 
mudaram, o impositivo de ser bela permaneceu. No quesito "seja feminina", a autora enfatizou a relação entre feminino e masculino, os processos de masculinização de mulheres e o imperativo de feminização de seus corpos: "O temor que a mulher rompa algumas barreiras que delimitam as diferenças culturalmente construídas para cada sexo torna imperiosa a sua feminização, caso contrário, diz o discurso dominante, ela estará se masculinizando." (Goellner, 2003, p. 107). Esse processo de feminização incide de forma contundente na aparência e no uso do próprio corpo. Certamente esse imperativo persiste na contemporaneidade. A feminização 'deve' estar estampada nos corpos de mulheres que devem se fazer femininos. Se o desejo de ser mãe hoje pode ser 'controlado', adiado, 'artificialmente' realizado, ele ainda ocupa um lugar central na vida das mulheres, tanto as que 'decidem' ter como as que optam por não ter filhos/as:

"Eu fiquei grávida num domingo de manhã... tinha um cobertor azul de lã escura... Mateus me pegou pelo braço e disse que ia me fazer a pessoa mais feliz do mundo. Me deu um CD gravado com todas as músicas que eu mais gostava. Ele disse que queria casar comigo ou então morrer afogado."

A narração inicial de "O Céu de Suely" opera como uma citação de algo que é (ainda) bastante esperado das (e pelas) mulheres: $\mathrm{O}$ que vemos e ouvimos nessa "citação"? Que corpo é esse que assume uma determinada posição de sujeito? Como entender a força performativa do gênero e da sexualidade nessa cena? É possível afirmar que enunciados performativos estão, desde essa abertura, produzindo uma direção, uma estrada para a feminilidade em questão? E que outros enunciados operam em direções divergentes a essa que parece reiterar a norma?

Nas palavras de Butler (1990, p.33): "Gênero é a repetida estilização do corpo, um conjunto de atos repetidos no interior de um quadro regulatório altamente rígido que se cristaliza ao longo do tempo para produzir a aparência de substância, de um tipo se ser natural."12 Gênero é entendido aqui como uma construção que se dá através de um conjunto de práticas reguladoras que impõem uma determinada ordem e coerência para os corpos e desejos. Essa construção do gênero fabrica uma aparência de fixidez do corpo e de seu 'sexo biológico'. A aparência de 'natural' e ‘estável' do corpo só é obtida a partir de inúmeras operações repetidas, disseminadas, impostas, desejadas e esperadas. Butler (1990, p. 24) analisa: “o gênero demonstra ser performativo - quer dizer, constituinte da identidade pela qual 
ele se faz passar, ou que ele simula ser. Nesse sentido, o gênero é sempre um fazer, embora não um fazer por um sujeito que se poderia dizer preexistente ao feito." 13 A autora nos desafia a pensar as categorias do gênero distanciando-nos da metafísica da substância e, para isso, apóia-se em Nietzsche quando esse afirma que não há um 'ser' por trás do fazer, não há um fazedor por trás da obra. O que há então? Apenas a obra. Butler (1990, p. 25) conclui: "não há identidade de gênero por trás das expressões do gênero; a identidade é performativamente constituída pelas próprias 'expressões' que se diz serem seus resultados."14

Sobre a afirmação de Beauvoir já tantas vezes citada, problematizada e ressignificada, Butler (1990, p. 33) comenta "Se há alguma coisa correta na declaração de Beauvoir de que não nascemos, mas nos tornamos uma mulher, segue-se que mulher é em si um termo em processo, um devir, um construir do qual não se pode dizer legitimamente que tenha origem ou fim." 15

Muitas teóricas (Butler, 1990, Louro, 2000, 2004a, 2004b; Scott, 1990; Meyer, 2004; Wittig, 1992) contestaram a supremacia da biologia nas teorizações feministas sobre o gênero. Nicholson (2000) argumenta que, mesmo teóricas que assumem uma perspectiva construcionista podem, por vezes, manter uma posição de "fundacionalismo biológico", não desestabilizando a noção de fixidez do corpo biológico, ou seja, muitas teorizações feministas, ainda que operem com a noção de construção, continuam supondo que há uma base ou fundamento biológico sobre o qual o gênero é construído. Dessa forma, a biologia parece pré-existir à cultura ou, em outras palavras, estaria fora da cultura. No entanto, como afirma Louro (2004b, p. 81) "Não há corpo que não seja, desde sempre, dito e feito na cultura; descrito, nomeado e reconhecido na linguagem, através dos signos, dos dispositivos, das convenções e das tecnologias."

Pode-se dizer que os processos de significação em torno dos corpos, gêneros e sexualidades, bem como todos os processos de significação de uma dada cultura, acabam por apagar as marcas de sua própria produção e historicidade. Analisar processos de significação implica em adentrar um terreno de indecibilidade. O significado é indecidível: é impossível chegar a um único e verdadeiro significado, há sempre várias leituras possíveis. Estamos condenados a sermos "intérpretes", dirá Foucault (2005b), ainda que o ato de interpretar sempre nos escape. Enquanto "intérpretes", interpretamos e perpetramos alguns signos e símbolos em detrimento de outros. 
Com isso, temos uma naturalização de práticas e 'verdades' que são repetidas e reiteradas. Desconfiar do que é tido como 'natural', como já assinalou Louro (2004a), talvez seja o nosso maior desafio. Diria que essa tem sido uma das principais estratégias dentro de uma atividade político-investigativa na perspectiva com a qual trabalho.

Para Butler (2000, p. 163), “A construção não apenas ocorre no tempo, mas é, ela própria, um processo temporal que atua através da reiteração de normas; o sexo é produzido e, ao mesmo tempo, desestabilizado no curso dessa reiteração." A autora problematiza a noção de construção subjacente às perspectivas construcionistas que colocaram em questão o sujeito do humanismo e, no entanto, por vezes, não deixaram de pressupor a existência de um sujeito que executa a construção a que se referem. Desta forma, a autora questiona:

Se o gênero é uma construção, deve haver um "eu" ou um "nós" que executa ou desempenha essa construção? Como pode haver uma atividade no ato de construir sem que pressuponhamos um agente que precede e desempenha esta atividade? Como poderíamos explicar a motivação e a direção da construção sem esse sujeito? (Butler, 2000, p. 160)
Retomo aqui a argumentação proposta por Louro (2004b) para afirmar que o processo de construção dos corpos, gêneros e sexualidades é contínuo, sempre inacabado e instável. Busco, nas palavras dessa autora, uma resposta provisória às questões lançadas por Butler:

Embora participantes ativos dessa
construção, os sujeitos não a exercitam
livres de constrangimentos. Uma matriz
heterossexual delimita os padrões a serem
seguidos e, ao mesmo tempo,
paradoxalmente, fornece a pauta para as
transgressões. É em referência a ela que se
fazem não apenas os corpos que se
conformam às regras de gênero e sexuais,
mas também os corpos que as subvertem.
(Louro, 2004b, p.17)

O sujeito generificado, antes de ser a causa ou a origem das instituições e práticas ou dos discursos, é o seu efeito. (Butler, 1990; Louro, 2004b) A norma regulatória do gênero está para além da constituição e produção de subjetividades. $\mathrm{O}$ gênero tem se mostrado um sistema muito mais amplo que se infiltra, de diversas formas, em práticas, objetos, produtos, além dos sujeitos. $\mathrm{O}$ gênero tem sido um organizador fundamental da cultura. Diferentes culturas, olhadas em pequenos contextos sócio-culturais, estão carregadas de marcas de gênero. 
A linguagem assume extrema relevância nesse processo, por se constituir, como afirma Wittig (1983, citada por Butler, 1990, p. 115), em um "conjunto de atos, repetidos ao longo do tempo, que produzem efeitos de realidade que acabam sendo percebidos como 'fatos'."16 E assim se constitui a 'realidade': na repetição de atos, acompanhados de palavras, gestos e olhares que produzem esses efeitos de 'verdade-realidade'.

Nessa mesma direção, a estudiosa Salih (2011), no livro intitulado "Judith Butler"17, afirma: "longe de ser neutra, a percepção e descrição do corpo ('É uma menina!', etc) é um enunciado interpelativo performativo, e a linguagem que parece simplesmente descrever o corpo efetivamente o constitui." Essa afirmação nos remete a dois conceitos formulados, respectivamente, por Althusser e Austin ${ }^{18}$ : interpelação e atos de fala performativos. Butler (2007) revisita esses conceitos e com eles propõe novos arranjos teóricos. A autora analisa os atos de fala como interpelação e argumenta que é possível ressignificar e criar espaços de resistência dentro dos limites da própria linguagem. Butler (2007, p. 15) define a interpelação como:

una apelación que se equivoca de blanco regularmente, requiere el reconocimiento de una autoridad al mismo tiempo que confiere identidad a través de su acto que implica forzar con éxito ese reconocimiento. La identidad es una función de esse circuito pero no es preexistente a él. La marca que hace la interpelación no describe; inaugura. Busca introducir una realidad más que informar de una realidad existente, y logra esta introdución a través de la cita de una convención existente.

Para que a interpelação seja efetiva, é preciso que o sujeito interpelado se reconheça como o sujeito que está sendo chamado. ${ }^{19}$ (Salih, 2011) Mais do que isso: "La interpelación no se dirige, como pretende, a um sujeto que ya existe com anterioridad a este acto, sino que lo produce en su misma operación." (Garcia, 2003, p. 5)

Antes de finalizar, apresento mais alguns fragmentos do filme que apontam na direção da interpelação e da resistência.

Na cena que segue, a tia de Hermila deixa explícito o sentimento que mantém por Georgina, a amiga que trabalha como profissional do sexo na cidade de Iguatu. Tia Maria é apresentada, ao longo da trama, com traços estereotipados na figura de uma lésbica - carrega marcas que, em nossa cultura, seriam consideradas "masculinas". Ela trabalha numa empresa que presta serviços de mototáxi. Desde o início fica evidente seu amor por Georgina. 
Ela parece não se importar com o fato de elas (ainda) não terem uma relação amorosa. Maria admira e expressa essa admiração por Georgina. Elas interagem em diferentes momentos. Na primeira cena que mostra um encontro entre elas, Maria apresenta Hermila à Georgina que, ao beijar-lhe o rosto, deixa uma marca de batom em Hermila; Maria não deixa escapar, dizendo em tom de brincadeira: "Em mim ela não deixa uma marca dessas”. O clima é de descontração, alegria e diversão. Elas conversam, riem, tomam cerveja, dançam e se divertem juntas.

A amizade existente entre Maria e Georgina e a amizade que nasce do encontro entre Hermila e Georgina apontam para um aspecto que ganha relevância no filme e talvez sinalize um deslocamento importante relativo às feminilidades.

Em outra cena, crianças brincam na praça à noite, jogando bola; enquanto Hermila e tia Maria caminham lentamente pela rua - ambas carregam sacolinhas plásticas. Acompanhamos o movimento e o diálogo delas em plano sequência. Tia Maria sorri enquanto conta animada para Hermila sobre o que planeja fazer para e com Georgina. Hermila escuta, fala pouco e se mostra mais fechada e séria nesta cena:
Tia Maria: "Comprei um biquíni pra dar de presente pra Georgina."

Hermila: "Eita!"

Tia Maria: "Vou chamar ela pra ir pra praia comigo lá em Fortaleza. Será que ela vai?"

Hermila: "Todo mundo gosta de praia."

Tia Maria: "To doida pra ver ela de biquíni se queimando no sol. Eita! Esqueci de comprar cigarro."

Tia Maria pede para Hermila segurar sua sacolinha e entra no armazém para comprar cigarro. Hermila lhe espera, séria e pensativa. Quando tia Maria retorna, Hermila lhe dá a notícia: "Eu vou me rifar, tia". Espantada, tia Maria pergunta: "O quê??" Elas estão paradas ao lado do armazém cuja fachada é dividida em duas cores que também dividem o plano de fundo da cena. Atrás de Hermila a parede é vermelha e há uma inscrição na parte superior que aparece por um segundo na cena: "Revenda" - na imagem essa inscrição fica acima da protagonista. Atrás de Maria, a parede é amarela, sem inscrições. Não apenas a parede está dividida aqui.

Hermila: "Vou me rifar, ficar rica. Comprar uma casa pra mim e pra Mateus, Mateuzinho."

Tia Maria: "Oxe! Que idéia de puta é essa?"

Hermila: "Puta nada. Puta trepa com todo mundo. Eu só vou trepar com um cara. 
Não quero ser puta, não. Não quero ser porra nenhuma."

Ao mencionar o termo "puta", o que está sendo citado? O que torna possível essa citação? O termo também carrega uma história, assim como outros tantos nomes comumente utilizados para insultar. De acordo com Butler (2007, p. 16) "los nombres injuriosos tienem una historia, una que se invoca y se vuelve a consolidar en el momento de la emisión, pero que no se dice explícitamente." A autora questiona como pode uma fala de ódio ser citada contra si mesma e qual o melhor uso que podemos fazer dessa repetição. Que força existe na repetição de um termo utilizado não apenas para designar a mulher que trabalha como profissional do sexo, mas para designar também um jeito de viver a sexualidade que a vincula à promiscuidade, vulgaridade e desqualificação do feminino? Quais seriam os parâmetros para indicar que uma mulher é puta?

Puta ou santa? Recatada ou vulgar? Essas dicotomias persistem na configuração de feminilidades contemporâneas. Essas dicotomias limitam, classificam, julgam, hierarquizam, legitimam e desqualificam determinadas práticas, corpos, sujeitos e desejos de acordo com os contextos em que são mobilizadas. Diria que o poder exercido através dessas dicotomias está produzindo e sendo produzido dentro de um quadro heteronormativo que segue impondo como deve ser uma mulher, um homem, um corpo, uma sexualidade, um gênero. A música que compõe o título desse texto é transcrita na íntegra a seguir por provocar um tensionamento nessas dicotomias, na medida em que opera com a conjunção "e" no lugar do "ou".

"Tantas, sou só uma e sou tantas
Sou devassa e sou santa
Recatada e vulgar
Louca, tão centrada e tão louca
Degustando em tua boca
As delícias de amar
Me respeita e me abusa
Me ame como
Simples demais ou confusa
Sou simplesmente mulher,

A rifa de Hermila poderia ser compreendida como expressão de sua agência, ou seja, uma forma de resistência dentro de uma certa contingência. Nas palavras de Salih (2011), o conceito de agência, para Butler significa oportunidades para subverter a lei contra si mesma com fins radicalmente políticos. Butler (2000) enfatiza que as normas são a condição de possibilidade de uma agência, as normas são o limite e a condição ao mesmo tempo. Dessa forma, Butler (2000, p. 170) compreende a agência "como uma 
prática reiterativa ou rearticulatória imanente ao poder e não como uma relação de oposição externa ao poder", lembrando que não se trata de uma prática voluntarista ou individualista que pressupõe um sujeito que escolhe. A ação do sujeito é constrangida, limitada e produzida a partir das normas regulatórias que o constituem.

Hermila une rifa, comércio e uma única noite de 'prostituição'. Nós, espectadores/as ficamos sabendo de sua ideia no mesmo instante em que inicia a venda da rifa. Utilizando os próprios códigos da cidade, códigos já conhecidos por ela e pelos/as moradores/as de Iguatu, põe em ação seu plano: a venda de uma rifa cujo prêmio é "uma noite no paraíso... comigo" e cujo valor "é quinze reais". Ela pretende, com essa rifa, juntar dinheiro suficiente para sair daquele lugar. Ela sonha em comprar uma casa para ela e Mateuzinho e depois ainda buscar a avó e a tia para irem morar com eles em algum outro lugar do Brasil.

Com a rifa, Hermila adentra um terreno arenoso, irregular, onde os limites que tentam definir quando, onde e por que uma mulher passa a ser considerada "puta" ou "profissional do sexo" são perturbados. Uma fronteira marcada por nuances e sentidos que variam muito de um contexto para outro. A ação de Hermila sugere uma linha de fuga, um ponto de resistência e essa ação acontece exatamente no campo da sexualidade.

Acredito que há tanto elementos subversivos como elementos normativos na rifa de Hermila, contudo vale notar como se torna difícil tentar 'classificar' o que exatamente ela está fazendo com seu corpo, com sua sexualidade. Há uma ideia de transgressão à medida que ela ultrapassa o que é permitido e normatizado - sua ação embaralha códigos e significados em torno do corpo e da sexualidade.

Ao oferecer a rifa, Hermila também interpela aqueles homens como homens heterossexuais que disputariam uma noite no paraíso com ela. Pela quantidade de dinheiro que arrecada, podemos imaginar que, de fato, a venda foi um sucesso, como mencionará tia Maria. No entanto, certamente a interpelação atingiu de modos distintos os diferentes homens de Iguatu.

Da forma como li, eu diria que "O Céu de Suely" aponta para formas de resistência às normas regulatórias do gênero, no entanto, em muitos momentos essas normas são reiteradas. Embora haja cenas onde a protagonista é constrangida e agredida a partir de julgamentos morais, parece-me que o filme nos conduz a um outro lugar: o convite talvez seja justamente o de suspender os julgamentos de um modo geral. E nessa suspensão, uma outra ética torna-se possível, uma nova experiência subjetiva entra em-cena-ação. 
Nessa/dessa posição, diria que não somos interpelados/as a julgá-la, nem a absolvêla. Acredito que somos levadas a acompanhar o seu movimento e, na medida do possível, fazermos o nosso.

\section{Notas}

1 Trecho da música "Simplesmente Mulher" de Silvia Machete. Recuperado em 15 de junho, de 2012 de: http://letras.terra.com.br/silviamachete/1408324/.

${ }^{2}$ Tese desenvolvida na Linha de Pesquisa "Educação, Sexualidade e Relações de Gênero", no Programa de Pós-Graduação em Educação da Universidade Federal do Rio Grande do Sul, com orientação da professora Dra. Guacira Lopes Louro. (Balestrin, 2011).

3 Coloco 'adolescência' entre aspas como forma de problematizar o termo e a concepção naturalizada das chamadas fases do desenvolvimento humano.

${ }^{4}$ Diz o autor: "Tentarei mais tarde fazer a história desta imensa 'ginecologia', no sentido amplo do termo." (Foucault, 1989, p. 234)

${ }^{5}$ Para mais detalhes sobre esse recurso metodológico, ver capítulo intitulado "Making Of" de minha tese (Balestrin, 2011).

${ }^{6}$ A ideia utilizada aqui é inspirada no título do primeiro capítulo do livro de Fischer (2006) - “A TV que vemos e a TV que nos olha" - que, por sua vez, apropriou-se de outro autor cujo livro intitula-se "O que vemos, o que nos olha" (Didi-Huberman citado por Fischer, 2006, p. 11).

7 Música de Marisa Monte, poema de Octávio Paz, versão de Haroldo de Campos. Recuperado em 15 de junho de 2012 de em

http://letras.terra.com.br/marisamonte/47272/

8 Ann Kaplan (1995); Teresa de Lauretis (2003); Laura Mulvey (1989, 1996) e Anneke Smelik (1993).

${ }^{9}$ Incluo aqui saberes produzidos no campo da psicologia, da psiquiatria e, talvez de um modo mais contundente, da psicanálise. "Foucault insiste quanto à função de normalização que desempenham os saberes: medicina, psiquiatria, psicanálise, psicologia." (Castro, 2009, p. 310).

${ }^{10}$ Neste texto intitulado "As mamas como constituintes da maternidade: uma história do passado?" Meyer (2002, p. 379-380) utiliza para análise "aspectos/informações extraídos, principalmente: da Lição 1 do Manual de Manejo e Promoção do Aleitamento Materno (Manual de 1993)...; do site que o Ministério da Saúde mantém para divulgar o Programa; de artigos de jornais do Rio Grande do Sul e, ainda, de folhetos informativos produzidos na Semana Estadual do Aleitamento Materno." 
${ }^{11}$ Foucault (2005a) descreve a histerização do corpo da mulher como um dos grandes conjuntos estratégicos de saber-poder desenvolvidos em torno do sexo a partir do século XVIII. (p. 99).

12 Exceto as citações em espanhol, as demais citações advindas de obras de outros idiomas estão traduzidas no corpo do texto e suas versões originais são colocadas em nota de rodapé: "Gender is the repeated stylization of the body, a set of repeated acts within a highly rigid regulatory frame that congeal over time to produce the appearance of substance, of a natural sort of being." (Butler, 1990, p. 33).

13 “'(..) gender proves to be performative that is, constituting the identity it is purported to be. In this sense, gender is always a doing, though not a doing by a subject who might be said to preexist the deed." (Butler, 1990, p. 25).

14 "There is no gender identity behind the expressions of gender; the identity is performatively constituted by the very 'expressions' that are said to be its results." (Butler, 1990, p. 25).

15 "If there is something right in Beauvoir's claim that one is not born, but rather becomes a woman, it follows that woman itself is a term in process, a becoming, a constructing that cannot rightfully be said to originate or to end." (Butler, 1990, p. 33).
16 "Language, for Wittig, is a set of acts, repeated over time, that produce realityeffects that are eventually misperceived as 'facts'." (Butler, 1990, p. 115).

17 Salih (2011) nos conduz às principais formulações butlerianas ou, como prefere chamar, às ideias-chave de sua obra que é considerada complexa e até mesmo controversa e, no entanto, tem sido utilizada em diversos contextos e campos de estudo. Em cada capítulo, a autora nos convida a percorrer uma das obras de Judith Butler, dando ênfase aos principais conceitos abordados nas mesmas: em "Gender", Salih (2011) refaz o caminho percorrido por Butler em "Gender Trouble", publicado em 1990, reeditado em 1999 e traduzido para o português somente em 2003.

${ }^{18}$ O filósofo britânico Austin publica, em 1962, o livro "How to do things with words", no qual reúne seus estudos sobre linguagem que culmina com a teoria dos atos de fala tão amplamente citada entre filósofos e estudiosos da linguagem. Seu trabalho aponta para o surgimento de "um novo paradigma teórico que considera a linguagem como ação, como forma de atuação sobre o real, e portanto de constituição do real, e não meramente de representação ou correspondência com a realidade." (Austin, 1990, p.10).

${ }^{19}$ O clássico exemplo de Althusser referese a uma cena em que um policial grita 
para um homem na rua "Ei, você aí!”. “Ao gritar, o policial interpela o homem como um sujeito, e ao se voltar o homem assume sua posição como tal.” (Salih, 2011, p. 4).

${ }^{20}$ Música já mencionada anteriormente, na primeira nota.

\section{Referências}

Adelman, M. \& Ruggi, L. (2007). Corpo, identidade e a política da beleza. Gênero: Revista do Núcleo Transdisciplinar de Estudos de Gênero, 7 (2), 39- 63.

Aïunouz, K. (2006). O Céu de Suely. VideoFilmes, Celluloid Dreams, Shotgun Pictures.

Austin, J. L. (1990). Quando dizer é fazer: palavras e ação; tradução e apresentação à edição brasileira Danilo Marcondes de Souza Filho; Porto Alegre: Artes Médicas.

Balestrin, P. A. (2011). O corpo rifado. Tese de Doutorado, Programa de Pós-Graduação em Educação, Faculdade de Educação, Universidade Federal do Rio Grande do Sul, Porto Alegre.

Bauman, Z. (2005). Identidade; tradução de Carlos Alberto Medeiros. Rio de Janeiro: Zahar.

Birman, J. (2001). Gramáticas do erotismo: a feminilidade e as suas formas de subjetivação em psicanálise. Rio de Janeiro: Civilização Brasileira.

Butler, J. (1990). Gender Trouble: feminism and subversion of identity. New York:

Routledge.

Butler, J. (1999). La vida psíquica Del poder. Teorías de la sujeción. Feminaria, (22/23), 1-13.

Butler, J. (2000). Corpos que pesam: sobre os limites discursivos do "sexo". Em Louro, G. L. O Corpo Educado Pedagogias da sexualidade. (2 ${ }^{\mathrm{a}}$. ed.). (pp. 151-172). Belo Horizonte: Autêntica, 2000.

Butler, J. (2003). O parentesco é sempre tido como heterossexual? cadernos pagu, (21), 219-260.

Butler, J. (2007). Sobre la vulnerabilidad lingüística. Feminaria, (30/31), 1-20.

Castro, E. (2009). Vocabulário de Foucault; tradução de Ingrid Müller Xavier. Belo Horizonte: Autêntica.

Costa, J. F. (1999). Sem fraude nem favor: estudos sobre o amor romântico. ( $5^{\mathrm{a}}$ ed.). Rio de Janeiro: Rocco.

Fischer, R. M. B. (2006). Televisão $e$ Educação: fruir e pensar a TV. (3 ${ }^{\mathrm{a}}$ ed.). Belo Horizonte: Autêntica.

Foucault, M. (1989). Não ao Sexo Rei. Em M. Foucault. Microfísica do Poder. $\left(8^{\text {a }}\right.$ ed.). (pp. 229-242.) Rio de Janeiro: Edições Graal. 
Foucault, M. (2001). O que é um autor? Em M. Foucault, M. B. Motta (Org); Estética: Literatura e pintura, música e cinema; tradução de Inês Autran Dourado Barbosa. Ditos e escritos III, (pp. 264-298). Rio de Janeiro: Forense Universitária.

Foucault, M. (2005a) História da Sexualidade - a vontade de saber. (16 ${ }^{\mathrm{a}}$ ed.). Rio de Janeiro: Graal.

Foucault, M. (2005b). Um diálogo sobre os prazeres do sexo - Nietzche, Freude Marx - Theatrum Philosoficum. (2 ed.). São Paulo: Landy.

Garcia, D. C. (2003). Identidad sexual y performatividad. Athenea Digital, (4), 1- 10.

Goellner, S. (2003). Bela, Maternal $e$ Feminina: imagens da mulher na Revista Educação Physica. Ijuí: Editora Unijuí.

Grossi, M. P. (2003). Gênero e parentesco: famílias gays e lésbicas no Brasil. cadernos pagu (21), 261280.

Kaplan, E. A. (1995). A mulher $e$ o cinema: os dois lados da câmera; tradução de Helen Marcia Potter Pessoa, Rio de Janeiro: Rocco.

Laqueur, T. (2001). Inventando o SexoCorpo e gênero dos gregos a Freud. Rio de Janeiro: Relume Dumará.

Lauretis, T. de. (2003). Imagenação. Caderno de Pesquisa e Debate do
Núcleo de Estudos de Gênero/UFPR, (2), 1-79.

Louro, G. L. (2000). Pedagogias da Sexualidade Em G. Louro. O Corpo Educado - Pedagogias da sexualidade. (2 ed.). (pp. 7-34). Belo Horizonte: Autêntica.

Louro, G. L. (2004a). Gênero, sexualidade e educação - uma perspectiva pósestruturalista.

( $7^{\mathrm{a}}$ ed.). Petrópolis: Vozes.

Louro, G. L. (2004b). Um corpo estranho - Ensaios sobre sexualidade e teoria queer. Belo Horizonte: Autêntica.

Meyer, D. (2002). As mamas como instituintes da maternidade : uma história do passado? Em F. Mercado, D. Gastaldo, C. Calderón. (Orgs.), Paradigmas y diseños de la investigación cualitativa em salud: una antologia iberoamericana. (pp. 375-402). Universidad de Guadalajara/ Centro Universitario de Ciencias de la Salud.

Meyer, D. (2004). Teorias e políticas de gênero: fragmentos de histórias e desafios atuais. Revista Brasileira de Enfermagem, 57 (1), 13-18.

Mulvey, L. (1989). Visual and other pleasures. (pp. 14-26). Bloomington and Indiana University Press.

Mulvey, L. (1996). Cinema e sexualidade. (tradução de Flávia Cesarino Costa) Em I. Xavier (Org.). O cinema do 
século. (pp 123-139). Rio de Janeiro: Imago.

Nicholson, L. (2000). Interpretando Gênero. Revista Estudos Feministas, 8 (2), 9-41.

Paulon, S. (2005). A análise de implicação como ferramenta na pesquisaintervenção. Psicologia e Sociedade, $17,18-25$.

Rial, C. S. (2005). Mídia e sexualidades: breve panorama dos estudos de mídia. Em M. Grossi. cols (Org) Movimentos sociais, educação e sexualidades. (pp. 107-136). Rio de Janeiro: Garamond.

Salih, S. (2011) Judith Butler; tradução de Guacira Lopes Louro, Belo Horizonte: Autêntica. (no prelo)

Scott, J. (1990). Gênero: uma categoria útil de análise histórica. Educação $e$ Realidade, 16 (2), 5-22.

Smelik, A. (1993). O que atinge o olhar: estudos fílmicos feministas; tradução de Guacira Lopes Louro. Em R. Buikema \& A. Smelik (Orgs.) Women's studies and Culture. A feminist introduction. Londres e New Jersey: Zed Books.

Soares, R. (2010). O Сéu de Suely: identidades juvenis e sexualidade. Trabalho apresentado no Seminário Internacional Fazendo Gênero 9, Florianópolis. Recuperado em 15 de junho, 2012 de http://www.fazendogenero.ufsc.br/9/ resources/anais/1277938473_ARQUI VO_RosangelasoaresOCEUDESUE LYtrabalhocompleto.pdf Swain, t. n. (2006). Entre a vida e a morte, o sexo. labrys, études féministes/ estudos feministas, Recuperado em 15 de junho, 2012 de http://www.tanianavarroswain.com.b r/labrys/labrys10/livre/anahita.htm

Vanoye, F., Goliot-Lété, A. (2006). Ensaio sobre a análise fílmica; tradução de Marina Appenzeller. (4 $4^{\mathrm{a}}$ ed.). Campinas: Papirus.

Wittig, M. (1992). The straight mind and other essays.New York.

\section{Patrícia Abel Balestrin:}

UNILASALLE - Canoas, Tecnosocial, Avenida Victor Barreto, 2288 - prédio 14, $2^{\circ} \quad$ andar.

CEP: 92010-000

patricia.balestrin@unilasalle.edu.br A A pesquisa relatada neste artigo foi desenvolvida entre 2008 e 2011 e contou com financiamento da CAPES, através da bolsa de Doutorado vinculada ao Programa REUNI.

É professora colaboradora nos cursos de Especialização em Formação Integrada Multiprofissional em Educação e Ensino da Saúde e de Especialização em Práticas Pedagógicas em Serviços de Saúde, ambos promovidos pelo Núcleo de Educação, Avaliação e Produção Pedagógica em 
Saúde (EducaSaúde) da Faculdade de

Educação/UFRGS. É membro do

GEERGE - Grupo de Estudos de Educação

e Relações de Gênero da UFRGS. Exerce a

função de psicóloga no projeto "Sujeitos em Ação: geração de renda e cidadania" desenvolvido pelo Tecnosocial do UNILASALLE - Canoas e também trabalha como psicóloga no Serviço de Convivência e Fortalecimento de Vínculos, no Instituto São Benedito - entidade conveniada com a FASC (Fundação de Assistência Social e Cidadania) em Porto Alegre.

Graduada em Psicologia (2001) pela Universidade do Vale do Rio dos Sinos. Mestre (2007) e Doutora (2011) em Educação pela Universidade Federal do Rio Grande do Sul. 